\section{Gentle care for mouth cancer patients}

For patients diagnosed with mouth cancer, effective cleaning is an essential part of their daily routine. However, due to their treatment they might find this uncomfortable or difficult.

Consider adding new tools to their home care, especially softer, gentler aids. The TANDEX UltraSoft range has solutions including toothbrushes and the FLEXI UltraSoft interdental brush, designed specifically for use after surgery.

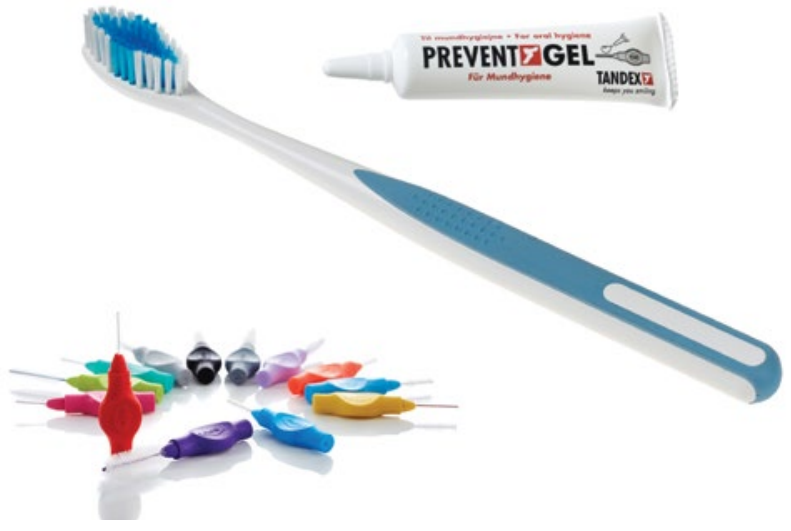

TANDEX is a premium brand of oral hygiene products. The UltraSoft brushes can be combined with TANDEX PREVENT GEL for even better performance.

Find out how TANDEX can help support and protect your most vulnerable patients.

For more information on Tandex's range of products, visit www. tandex.dk.

\section{Award-winning thumb and finger guard}

Thumbsie has recently won an Innovation of the Year award at the Dentist Industry Awards. Thumbsie is a brand of fabric thumb and finger guard designed for children who want to stop digit sucking, but need some extra help to change their behaviour.

A Thumbsie fabric guard can help curb the habit as it is a gentle and effective way to help children to give up which, left unchecked, can lead to a number of dental anomalies including orthodontic and breathing problems, as well as providing a source of persistent infections. The brand is available in thumb and finger guards in five

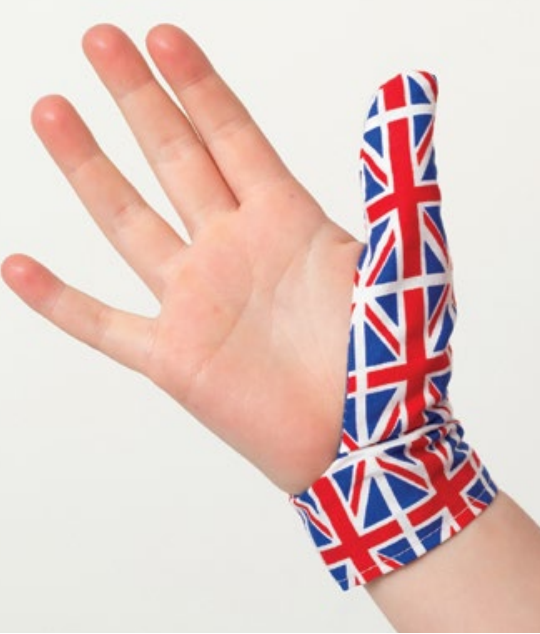
different sizes and should be worn day and night until the habit is broken. As well as the digit guards, a reward chart, a story book, and support via Thumb Sucking Clinics and the company website are all available to the parent.

Competition was particularly strong in the innovation category with 13 other companies reaching the finals, primarily those which

\section{Painlessly monitor tooth surfaces}

The CALCIVIS imaging system enables dental professionals to accurately monitor the tooth surfaces for activity over time. The screening procedure is completely painless and it can be used with patients from the age of six.

Using a bioluminescent photoprotein, the CALCIVIS imaging system detects free calcium ions as they are released from actively demineralising tooth enamel. It then captures this information and generates definitive visual evidence of dental erosion and caries at the very early stages. This enables preventive, non-invasive measures to be implemented immediately to reduce the risk of further disease progression.

For more information visit www.calcivis.com, call on 0131658 5152 or email at info@calcivis.com.

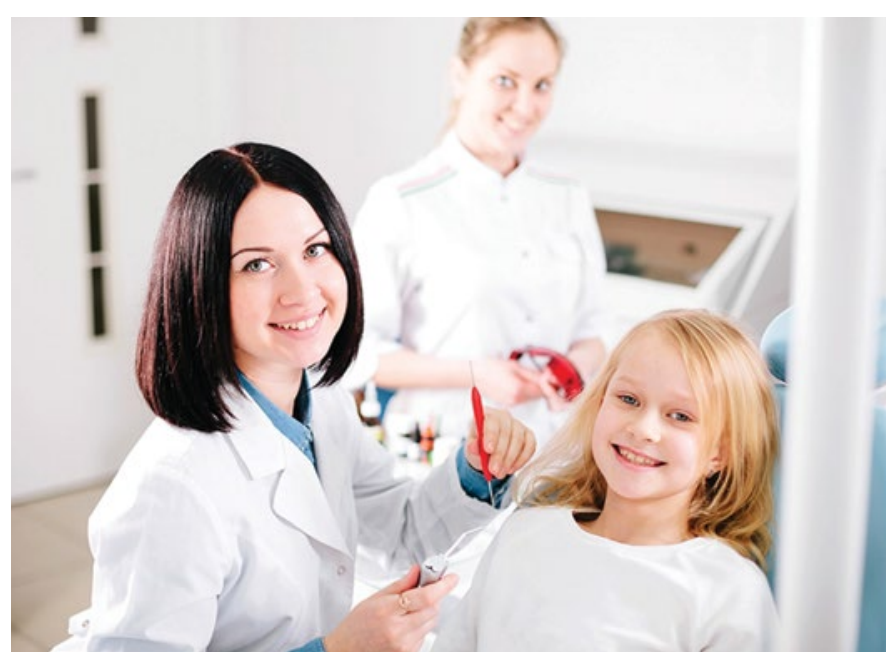

offer technology-based innovation to the dental profession including 3D scanners, teeth apps, industry-leading digital imaging and software, marketing \& SEO and dental management software.

The company behind Thumbsie works closely with the dental sector to offer a gentle solution to a problem which can cause damage to teeth and palate and now it has been recognised by the industry for its solution to preventing dental problems which are caused by sucking and which can lead to the need for interventional treatment in the future if left unchecked.

If a dental professional wishes to recommend Thumbsie, the company provides them with the following point of sale materials:

- Thumbs up for Ted's Thumbsie Book free of charge for their waiting room

- A tent display card

- Leaflets offering their patients $10 \%$ discount

- A sample of thumb and finger guard.

One of the company's most recent innovations is the introduction of an affiliate programme for dental professionals so that practices can recommend the Thumbsie brand by directing patients to its website where sales are tracked and commission paid for every sale.

For more information, visit https://thumbsie.co.uk/ or contact hello@thumbsie.co.uk. 